\title{
The Need for a Contextualized and Trans-disciplinary Approach to Human Security
}

\author{
Laurent Goetschel*
}

\begin{abstract}
Up until now, the most interesting attribute of human security which consists of the combination of a narrow focus concerning security issues, being individuals and groups, with a broad perspective of security threats, has failed to be exploited to its full potential. In this article, the author argues that this is predominantly due to the lack of a suitable approach and methodology which is able to incorporate the variety of existing human security constellations. Within a syndrome-based approach, human security should allow for a specific »clustering « of core problems based on a security perspective. This should provide new insights, in particular on the »variable « or context-specific part of human security and have important implications for comprehensive and coherent policy intervention strategies.
\end{abstract}

Keywords: Kontextualisierung, menschliche Bedürfnisse, menschliche Sicherheit, Friedenskonsolidierung, Syndrome Mitigation.

$\mathrm{H}$ uman security provides a direct link between the concept of security and human beings. In this sense, it is comparable to other concepts such as human rights or human health. However, the subject matter of human security is far less clear than that of human rights or human health: At its core, human rights relies on a broad consensus and forms part of codified and customary international law. The notion of health has a scientific basis and forms the uncontested objective of a whole branch of science. Compared to both of these concepts, human security, though its label implies universal aspirations, is a very ill defined concept. Numerous discussions have led to a variety of definitions of which some are broad, incorporating and also including freedom from want, and others are narrow and limited to the effects of violent conflicts. However, until now the most interesting attribute of the concept of human security as detailed above, has failed to be utilised to its full potential. As previously mentioned, this article represents an attempt by the author to justify his belief that this is essentially due to the lack of a suitable approach and methodology to incorporate the variety of existing human security constellations. The argument will be developed in four steps, looking at conceptual, policy, and research aspects of human security before making the case for a closer link between human security and regional contexts within the framework of an ongoing research programme on the mitigation of the syndromes of global change. ${ }^{1}$

\section{The Human Needs Approach}

The concept of human security relates the term of "security « to that of »humans «. Whereas in the past, the majority of

* Dr. Laurent Goetschel is Professor in Politics at the EuropaInstitut, University of Basel, and Director of swisspeace - Swiss Peace Foundation, Berne, Switzerland. This article was prepared with the support of the Swiss National Centre of Competence in Research North-South (NCCR North-South). An earlier draft was presented at the ACUNS seventh annual meeting in Geneva, 30 June - 2 July 2004. The author wishes to thank Albrecht Schnabel, Linda Shepard and the S+F editorial team for their most valuable comments.

1 Further information on this project is available online at http:// www.nccr-north-south.unibe.ch. security discourses were related to collective entities such as states or regions, human security puts the emphasis on individuals: considering why and how their security is at stake and how these issues should be dealt with. In human-security debates and policies, individuals are the $»$ referent« object.

So, what do we understand by security? »Security « points to some degree of protection of very important values that have been previously acquired. A nation may be deemed to be secure to the extent to which it was not in danger of having to sacrifice its core values. While the notion of wealth is measured in terms of the amount of a nation's material possessions, and power is measured in terms of its ability to control the actions of others, security, in an objective sense, measures the absence of threats to acquired values, in a subjective sense, it measures the absence of fear that such values will be attacked. ${ }^{2}$

In analogy, human security describes a situation in which individuals feel safe from attacks on their core values. But what are those values? Who defines them? And are those values supposed to be universal? Or are they dependent on specific cultural and socio-economic situations? Within the realm of peace and conflict research, such reflections on core values can be linked to the concept of »human needs «.

The human needs approach in regard to international relations studies rests on the basic assumption that human needs are a key motivational force behind human behaviour and social interaction. These needs could not possibly be subject to authoritative control. However, they should be subject to some form of government protection. The stability of social systems depends on these needs being satisfied. Social systems must be responsive to human needs if they are to maintain their legitimacy and survive intact in the long run. Social systems that fail to satisfy human needs will grow unstable and be forced to undergo some sort of change, leading to conflict and possibly violence. Human needs theorists suggest that the concept provides social sci-

2 Arnold Wolfers, Discord and Collaboration. Essays on International Politics, Baltimore and London 1962, p. 150 
entists with an important tool that will facilitate a more comprehensive and realistic understanding of the sources of motivation that underlie micro-level behaviour. ${ }^{3}$

Human needs theorists have distinguished themselves from the realist approach of international theory, which assumed that human nature was a priori evil and aggressive. ${ }^{4}$ The range of human needs was thus limited to the pursuit of power, security and prestige. The human needs approach proposed, among other things, to replace this rather simplified assumption about human nature which was used by »realists « with a more realistic set of assumptions and to open up these assumptions to detailed investigation and analysis. Thus, the approach pointed towards a more comprehensive and realistic understanding of human behaviour, both in terms of larger social aggregates, including various social and political groups and organisations, as well as states. ${ }^{5}$

Nevertheless, the problem of identifying exactly what human needs were remained. No consensus existed regarding this crucial definitional question. Should human needs be defined and understood as some minimum set of universal needs common to all individuals everywhere? Or, ought they be understood as culturally relative, varying from one context to another? ${ }^{6}$ The question is about the degree to which needs are determined by society and the process of socialization, as opposed to being ontological, universal needs, shared by all individuals. If the pursuit of human needs does in fact vary across cultures, one would expect needs to be viewed differently by peoples of different cultures. It has also been argued that, over time, industrialization and technological progress tended to produce a gradual raise in number and change in human needs. ${ }^{7}$

This issue of ontological versus culturally acquired and modified human needs gives rise to the question of a hierarchy of human needs: Are certain human needs more important than others? Does such a hierarchy follow the separation between ontological versus culturally acquired human needs? The question of hierarchy gives additional emphasis to the challenge of defining human needs. While some ontological human needs could be assumed on a normative basis, this is not the case for socially acquired ones: Social scientists cannot »see human needs empirically. It is something which has to be observed by some sort of indirect means.

The explanatory potential of the human needs approach exceeds the level of individuals. The assumed existence of human needs causes individuals to come together into

3 Jerel A. Rosati, David J. Carroll and Roger A. Coate, »A Critical Assessment of the Power of Human Needs in World Society«, in John Burton and Frank Dukes, eds., Conflict: Readings in Management and Resolution, Basingstoke 1990, pp. 156-159; John W. Burton, Conflict: Human Needs Theory, New York 1990; John W. Burton, "Conflict resolution as a political philosophy«, in Dennis J.D. Sandole and Hugo van der Merwe, eds., Conflict resolution theory and practice. Integration and application, Manchester 1993, pp. 57-58.

4 Kenneth N. Waltz, Man, the State and War, New York 1959.

5 Rosati et al. 1990, p. 160.

6 Katrin Lederer, ed., Human Needs: A Contribution to the Current Debate, Cambridge MA 1980, pp. 1-14.

7 Roy Ramshary, »Human Needs and Freedom: Three Contrasting Perceptions and Perspectives «, Alternatives No. 5 (1979-80), pp. 195-212. various social groupings which aggregate at some level to create »society«. Thus, a human needs approach should also allow for the building of bridges between different levels of analysis focusing on the aggregation of individuals into groups and social networks. Additionally, the human needs approach enables one to examine the implications and impact of international institutional arrangements both on individuals and groups. It can serve as a yardstick with which the desirability and efficacy of real world policies and political events can be evaluated in terms of promoting progressive social change.

Let us now turn our attention back to human security, a concept which the author sees as being closely related to that of human needs. Essential values at the individual level, which are perceived as being relevant to security by the people concerned, should be related to human needs. One may think of food security in drought situations, of health security in the context of widely spread diseases, or of political or cultural security when the rights of the minorities are seriously abused. Events at the regional level may be seen to threaten peoples' physical security. However, the inverse is not necessarily true: human needs are not always linked to security values. Affective human needs, for example, are not usually seen as being security relevant. If the core values of human security are linked to human needs, they should follow their logic and be divided into »ontologically given « and "variable« values. For the latter, the author suggests replacing the cultural factor with a more general context factor, as he assumes that other context related variables, such as geography, resource degradation or economic development also influence the perception of threats to core values.

\section{Human Security Policies}

The international political discovery of the human security concept is commonly linked to the publication of the UNDP 1994 Human Development Report. It offered a very broad definition of human security which contained dimensions related to freedom from fear (personal, community and political security) as well as dimensions of freedom from want (economic, food, health and environmental security). ${ }^{8}$ The Canadian Foreign Ministry concentrated on the freedom from fear and defined human security as the freedom from pervasive threats to people's rights, safety or lives, and including physical threats, quality of life, fundamental human rights, the rule of law, good governance, social equity, the protection of civilians in conflict and sustainable development. ${ }^{9}$ This definition comes closer to the political practice of the Human Security Network (HSN), which was launched in May 1998 at the initiative of Norway and Canada. ${ }^{10}$ It has narrowed down human security to an um-

8 United Nations Development Programme, Human Development Report 1994, New York 1994, p. 24.

9 See http://www.humansecurity.gc.ca/psh-en.asp.

10 See http://www.humansecuritynetwork.org. Other participating states are Austria, Chile, Greece, Ireland, Jordan, Mali, the Netherlands, Slovenia, Switzerland, Thailand, and, as an observer, South Africa. 
brella concept which includes policies pursuing the abolition or limitation of instruments of violence such as antipersonnel mines, small arms and policies aiming at the protection of especially vulnerable groups of persons such as children, women or internally displaced people. The network's highest quality lies in its capacity to bring together so called »like-minded « countries from the North and South around issues relating to human security and having held this form of gathering for several years. The HSN has achieved a number of results, in obtaining a high priority status for selected items of human security within the network and in their home countries and helping to put those items on the international agenda. The Japan-initiated Commission on Human Security, which adheres to the broader understanding of human security, has also helped in raising awareness. ${ }^{11}$ Established in 2001, it delivered its comprehensive final report in 2003 and organized a series of events in order to disseminate its conclusions and recommendations. $^{12}$

Aside from these explicit and institutionally framed human security policy activities, some related policy debates have been conducted with at least implicit normative reference to human security. The first debate concerns the so-called $» r e-$ sponsibility to protect «. Globalisation has increased the significance of individuals as objects of international security. Their rights are no longer systematically ignored when weighed up against the prerogatives of state sovereignty. However, whereas international governance is increasingly judged according to its capacity to provide protection to individuals, the increased awareness is not accompanied by precise norms and even less by means with which to handle the new conditions. ${ }^{13}$ Academic work and reports have greatly improved the structure and methodology of the debate, but still lack an impact on the political handling of these issues. ${ }^{14}$ In fact, the political sensitivity in regard to this question seems to have diminished again since its most recent culmination around the 1999 Kosovo war. ${ }^{15}$

The second debate concerns so-called »failed « states. The success of "modern « Western states can be related to their unprecedented capacity for bringing security in its most basic sense (freedom from fear) to the lives of ordinary people. Accordingly, the apparent failure of many states in other parts of the world, especially in Africa, has been studied largely in terms of what they lack when compared to the traditional Western state concept i.e. their lack of protection for individuals. But what exactly are the human security needs of the inhabitants of such states? And to what extent are these needs actually met or abused by the political authorities responsible? Being aware that such states may follow a different logic and fulfil different functions, the

11 See http://www.humansecurity-chs.org

12 See http://www.humansecurity-chs.org/finalreport.

13 Laurent Goetschel, »Globalisation and Security: The Challenge of Collective Action in a Politically Fragmented World «, Global Society 14(2) 2000, p. 272.

14 See as most comprehensive example: The Responsibility to Protect, Report of the International Commission on Intervention and State Sovereignty. International Development Research Center, Ottawa, 2001.

15 Albrecht Schnabel and Ramesh Thakur, eds., Kosovo and the Challenge of Humanitarian Intervention: Selective indignation, collective action, and international citizenship, Tokyo, New York, Paris 2000. concept of human security should allow for a flexible and context-relevant analysis based on the actual security needs and taking into account any possible contributions of nonstate actors in providing security.

A third issue concerns the so-called "securitisation « of debates on complex humanitarian and political emergencies. Throughout the 1990s, arguments promoting the »securitisation « of such constellations were advanced by humanitarian lobbyists as they attempted to generate greater international engagement, and by security analysts who were genuinely concerned about the threats that zones affected by state collapse might pose. Both humanitarian and security actors tried to obtain a higher priority for such situations on the international political agenda, but had very limited success. This changed dramatically in the wake of the terrorist attacks of 11 September 2001. Since then, states, and especially »collapsed « states like Somalia, have drawn new attention as potential safe havens for transnational terrorist groups. ${ }^{16}$ It remains to be seen, however, whether this will strengthen human security or not in the long run. The diagnostic that a state »failed « or »collapsed « may prompt international action based on the »responsibility to protect «, leaves open the question of who shall be protected, from what threat, for which purpose, and by whom?

Thus, human security provides a conceptual framework for a general debate transcending traditional frameworks. Regarding the debate on international interventions, reflections on human security may complement the common legal arguments. Regarding so-called »failed states«, human security analysis should compensate for the deficiencies of discussions based on a purely Western state concept. As far as the issue of »securitisation « is concerned, taking into account human security may prevent inadequate intervention strategies from being conceived.

In summary, it can be said that human security has entered the policy realm, both from a definitional and from an institutional point of view. Conferences are being held, country reports are written and debates on the relative importance of the protection of individuals as compared to the one of state sovereignty take place. However, for all these discussions, one would like to know more about the content of human security, especially regarding its variable and context-specific part. Thus far, hardly any efforts have been undertaken in this respect. Human Security has been discussed at a general and aggregated level. It has been used to promote security issues relevant to individuals, such as landmines, small arms or child soldiers. But all this occurs in a rather vague and implicit normative way, usually with a rather weak (if any) implication of southern countries and without any discernable ambition to contextualize and thereby meaningfully fill the human security concept. This is largely due to a lack of proper methodology, which would be required in order to know more about human needs and respective human security core values. We will now con-

16 Ken Menkhaus, Somalia, State Collapse and the Threat of Terrorism, New York 2004 (Adelphi Paper 364), p. 7. 
sider various opportunities and challenges in creating such a methodology.

\section{Human Security Research}

From a security studies or peace research perspective, human security offers several opportunities: It is based on a comprehensive approach to security; it focuses on non-military threats, on the living conditions of individuals, and on threats occurring mainly within societies. In this respect, human security bears a strong agenda of transformation which addresses how security should be thought about and how one should act vis-à-vis the sources of human insecurity. Human security may serve as a label for a broad category of research in the field of security studies that is primarily concerned with non-military threats to the safety of societies, groups, and individuals, in contrast to more traditional approaches to security studies that focus on protecting states from external threats. ${ }^{17}$

A good example is environmental security. In effect, much of the effort to give a clearer focus to the concept of human security and use it as a basis for analysis has been undertaken by scholars in the field of environmental security, discussing among other issues questions of access to resources and livelihood. ${ }^{18}$ Factors discussed that border on the concept of environmental security fit fairly well into the »scheme« of human security, as individuals (i.e. groups of individuals) are the primary victims of environmental degradation and resource depletion. Environmental security factors are typical non-military security factors and environmental security research draws on a broad understanding of security and conflict factors. One might add that environmental security case studies are or should be context based, and that, additionally, environmental issues often provide the neutral »non-threatening « ground on which individuals and communities with few resources build up their voice and participate effectively in project planning, design and implementation. ${ }^{19}$ However, up until now, neither contextualization nor participative discussions, which would have included concerned individuals in the research process, have been high on the agenda of human security research.

Other scholars have focused on the process side of human security, looking at the way human security achievements are obtained. They have pointed at the impact of coalitions of smaller states or middle powers in offering bridging solutions while being incapable of providing a collective good within the realm of human security on their own. Together with the support of larger powers at certain critical moments and the initiative of non-state actors, these »middle states « may play the main role in promoting international norms in the field of human security. The diversity of interna-

17 Roland Paris, »Human Security: Paradigm Shift or Hot Air?«, International Security 26 (2) 2001, p. 96.

18 Richard A. Matthew, In Defence of Environment and Security Research, ECPS Report 8, 2002, p. 117.

19 Sanjeev Khagram, William C. Clark and Dana Firas Raad, »From the Environment and Human Security to Sustainable Security and Development «, Journal of Human Development 4 (2), 2003 p. 295. tional coalitions in both the horizontal (state-to-state) and vertical (state-civil society) sense may well be critical to the human security enterprise. ${ }^{20}$

The vague definition of the concept makes it all the more interesting to look at the language in use in order to attribute content and function to human security. Securitisation and discourse analysis literature finds its tribute in this field. ${ }^{21}$ Other schools of thought try to adopt a narrower definition so as to be able to quantify degrees of human security and possibly develop index-type tools. King and Murray offer a definition which includes only essential elements, meaning elements that are important enough for human beings to fight over or to put their lives or property at great risk for. They identify five key indicators - poverty, health, education, political freedom, and democracy - and incorporate them all into an overall measurement of human security for individuals and groups. ${ }^{22}$ Andrew Mack and his team have been working on the publication of an annual Human Security Report, which would map criminal violence and armed conflict based on existing and newly developed data sets. ${ }^{23}$

The problems of all these types of efforts which have been undertaken to date are twofold: Firstly, they identify certain values as being of greater importance than others without providing a clear justification for doing so. Though one understands the necessity for this, one is left with a rather strange feeling about the absence of a declared normative basis for this identification. Secondly, they apply their definitions on a universal basis, thereby claiming the implicit universal validity for the ranking that they established between different needs for purpose of definition.

Thus, one reaches a conclusion that is not dissimilar from that reached on the policy aspect of human security: The latter has definitely entered the field of research, and there are promising tracks to be followed, such as the one on environmental conflicts. However, the persisting difficulties in getting to grips with the concept and nailing it down to a tangible and context- specific content have, as is the case in the policy field, limited its added value.

\section{Trans-disciplinary Contextualisation}

As demonstrated above, the concept of human security bears a lot of potential, both from an intellectual academic perspective as well as in respect to actual policy challenges

20 Fen Olser Hampson with Holly Reid, »Negotiating Human Security. A New Kind of Multilateral Diplomacy? «, Paper prepared to be presented at the Annual Meeting of the International Studies Association, New Orleans, 24-27 March 2002.

21 According to Colleen O'Manique (»The 'securitization' of Africa's AIDS pandemic: whose security? «, Paper prepared to be presented at Annual Meeting of the International Studies Association, Montreal, 17-20 March $2004)$, the global AIDS pandemic, has apparently shifted from one of »health crisis« to a »security crisis «.

22 King, Gary and Christopher J. L. Murray, "Rethinking Human Security", Political Science Quarterly, 116 (4) 2001, pp. 585-610.

23 See http://www.humansecurityreport.info. For observations on the feasibility of such a report see Andrew Mack, »Report on the Feasibility of Creating an Annual Human Security Report «, Program on Humanitarian Policy and Conflict Research, Harvard University, February 2002. 
the field of peace-building and development. On the methodological side, initial efforts have been made in order to come to grips with the challenge of the concept's vagueness. However, in order to make use of the concept's theoretical and practical potential, at least three major problems still need to be tackled: these are the absence of a declared normative basis for the "core " needs that form the backbone of human security, the lack of conceptual efforts in determining the »variable « needs linked to human security, and lacking methodological efforts in determining these »variable « needs. The latter cannot be assumed only on the basis of implicit universal norms or available data sets. It is essential that normative assumptions for universal human needs be explicit and be justified or at the very least explained. Furthermore, means have to be found to elucidate »variable« needs and their context-specific significance.

In looking for ways to solve these problems, the syndrome mitigation approach used by the Swiss National Centre for Competence in Research (NCCR) North-South contains important theoretical as well as methodological inputs. The first input concerns the syndrome concept, which provides a possible conceptual support for our objective to contextualize human security.

A »syndrome « can be understood as a cluster of political, social, ecological and other core problems, which occur in particular combinations and in specific spatial and social contexts, and which have impacts that are detrimental to sustainability. These combinations of core problems form certain patterns or »typical clusters « that are based on similar processes, and emerge in different regions of the world. A »typical cluster « of core problems is accordingly designated as a »syndrome of global change ${ }^{24}{ }^{24}$ The strength of »syndromes « as analytical concepts results out of their inherent flexibility and regional adaptability. Still, they consist of declared contents and may be replicated in different regional contexts. As such, they offer a good compromise between case specific »uniqueness « and context-blind aggregation attempts. Syndrome »mitigation « are measures taken by individuals or institutions in one or more areas of interaction, which help to reduce the effects of single or combinations of several core problems, thereby reducing the negative impacts of global change, and contributing to sustainable development.

The second input concerns the methodology used by the NCCR North-South in order to identify syndromes and possible answers to them. The research program combines the syndrome concept with a »trans-disciplinary « approach. The latter is used to identify the constitutive core problems of syndromes, but also to help develop approaches to mitigate the syndromes. The challenge consists in developing participatory approaches allowing the transfer of local expert

24 Hans Hurni, Urs Wiesmann, Pascale Anton and Peter Messerli, »Initiating Research for Mitigating Syndromes of Global Change in Different Contexts «, in Hans Hurni, Urs Wiesmann and Roland Schertenleib, eds., Research for Mitigating Syndromes of global Change. A Trans-disciplinary Appraisal of Selected Regions of the World to Prepare Development-Oriented Research Partnerships, Perspectives of the Swiss National Centre of Competence in Research (NCCR) North-South, University of Berne, Vol. 1, Berne 2004, p. 37. knowledge into more comprehensive conceptual structures, whereby one way of proceeding may be to comment on already existing structures and possibly revise them. ${ }^{25}$ Cross or trans-disciplinary research is interdisciplinary, context-specific and participatory, both with respect to problem identification as well as in the search for and implementation of research-based solutions to development problems.

One specific objective of the NCCR North-South is to contribute to improving scientific knowledge about the prevention of conflicts related to syndromes of global change and to the degradation of natural resources and to promote the practical implementation of its results. ${ }^{26}$ This research dimension of the NCCR North-South provides the material link to human security, which - as explained - can be seen as an essential condition for the stability of social systems. But there are further interesting links between human security and the overall syndrome mitigation approach of the NCCR North-South.

From an NCCR approach, at a general conceptual level, human security may be seen as stressing the social dimension within sustainability's three pillars of environment, economy and society. On an operational research level it may be assumed that a human security »lens « will allow for the specific »clustering « of core problems based on a security perspective. Compared to a general sustainability approach, this specific »human security cluster « can be expected to emphasize problems linked to »core values «, that are perceived as $»$ urgent $«$, and as $»$ political $«$.

Human security - like sustainability - is primarily a normative concept and can only be meaningfully understood within a particular social context. While sustainability is used to negotiate and establish values and aims in processes of development, human security is used to clarify security relevant core values. A trans-disciplinary and contextspecific approach should provide insights especially into the »variable« or context-specific part of human security, but also on context-specific receptions of "core values and human needs attached to them.

Regarding mitigation, efforts to reach an agreement at the global level are much less likely to be effective than suitably contextualized efforts. Human security proponents would do well to empower people to identify what they see as the critical insecurities and the best means for promoting security. ${ }^{27}$ Policies must be adapted to variable »security packages «, i.e. specific clusters of threats and core problems.

In order to get a first impression regarding the feasibility of contextualizing human security in a trans-disciplinary setting, small pre-tests were carried out within the framework of the NCCR North-South in Ethiopia and in Côte d'Ivoire during 2004. In both cases the work included both academ-

25 See the corresponding reflections on Group Model Building tools, in Martin Cassel-Gintz, Group Model Building - A Transdisciplinary method of Knowledge Integration for the NCCR North-South, NCCR North-South Working Paper no. 3, Berne 2004.

26 See the corresponding work of the NCCR North-South individual project 7 (IP7) located at swisspeace - Swiss Peace Foundation (http://www.swiss-peace.org).

27 Khagram 2003, p. 301. 
ics and NGO representatives. However, the group involved in Côte d'Ivoire was larger, comprising a greater number of politicians and concentrated on a specific region in the West of the country (Parc de Taii), where conservation interests conflicted with development interests, and where the nearby border to neighbouring Liberia in the west and the demarcation line between the "forces nouvelles « and government forces in the north contributed to a particularly challenging constellation. The following remarks therefore concentrate on the second setting and, more specifically, on the results of a specific brief mission into the region which was followed by a three-day workshop with local, regional and national stakeholders that was conducted in the country's capital, Abidjan. Overall, the following guiding principles for research can be extracted from these experiences: The concept of human security can be introduced to people in a way which enables them to rapidly give meaningful inputs in order to clarify the context-specific content of the term. Discussions on human security allow human needs to be reviewed and ranked within heavily politicised environments without getting lost in political and national security debates. The tentative results showed an interesting mix of security dimensions including both military and nonmilitary ones and counting traditional »core values « (freedom from fear) as well as values which might be less imperative from a traditional »Northern « perspective but are of the greatest sensitivity in the specific context that is being considered, such as health or access to resources (freedom from want).

More concretely, the proliferation of small arms was of concern to all types of stakeholders, be they national, regional or local. Partly linked to the small arms issue, cross-border smuggling with Liberia proved to be of greatest concern to the people from the immediate neighbouring region. As concerned the central authorities, tensions between development and conservation interests had increased as a consequence of the national political conflict (between »forces nouvelles « and government forces), mainly due to the lack of control demonstrated by the central government in the region and the Parc de Taï during that time, and due to additional problems in marketing regional agricultural products. However, and interestingly, the occasional military strives between »North « and »South « and the accompanying rhetorical political exercises were not really seen as particularly threatening security issues.

Accordingly, if one were to reflect on intervention strategies in Côte d'Ivoire - something that was not done during the workshop - and especially strategies focusing on the southwestern part of the country, these strategies would not necessarily have to concentrate primarily on mitigating the protracted military conflict, but on cross-border trade issues, on small arms in particular, on health and water issues, and on the creation of sustainable (agricultural) development strategies for the populations concerned. Such strategies would have to accommodate development as well as conservation issues, the latter being essential for long term access to resources.

\section{Conclusions}

Ways need to be found in order to link the "global « human security discourse at the policy and academic level to local needs and perceptions and there is therefore a great need for additional in-depth case studies on human security situations. These studies should be based on participative processes and take into account the fundamental security needs of the populations concerned on a national or sub-national basis. The studies should be comparable and moderately aggregated in order to obtain the necessary relevance to existing policies. Thus, before looking for new highly aggregated Human Security Indexes, tools and measurement methods for specific human-security situations should be developed, giving an adequate picture of how the people involved perceive their security environment. This might be particularly useful in gathering additional insights on the so-called »new « determinants of security, such as the link between the wealth held by individuals and their sense of personal security, ${ }^{28}$ which comes close to the thesis that the most vulnerable within a society tend to rearticulate the society's security concept in their own terms. ${ }^{29}$ All in all, further improvement to the participative methodology used and the development of the way in which proper case studies are designed should allow for more interesting research results with important implications for comprehensive and coherent policy intervention strategies.

28 Stephen Gill, »Social Reproduction of Affluence and Human In/security on a Universal Scale«, Paper prepared and presented at the Annual Meeting of the International Studies Association Annual Meeting, Montreal, 17-20 March 2004.

29 Mely Caballero-Anthony, »Re-visioning Security in Southeast Asia«, Paper prepared and presented at the Annual Meeting of the International Studies Association Annual Meeting, Montreal, 17-20 March 2004. 